Vietnam Journal of Mechanics, VAST, Vol. 29, No.4 (2007), pp. 529-538

\title{
A NEW FINITE ELEMENT FOR FREE VIBRATION ANALYSIS OF STIFFENED COMPOSITE PLATES
}

\author{
TRAN ICH THINH \\ Hanoi University of Technology \\ NGO NHU KHOA \\ Thainguyen University
}

\begin{abstract}
A new 6-noded stiffened triangular plate element for the analysis of stiffened composite plates based on Mindlins deformation plate theory has been developed. The stiffened plate element is a combination of basic triangular element and bar component. The element can accommodate any number of arbitrarily oriented stiffeners and obviates the use of mesh lines along the stiffeners. Free vibration analyses of stiffened laminated plates have been carried out with this element and the results are compared with those published. The finite element results show very good matching with the experimental ones.
\end{abstract}

\section{INTRODUCTION}

Eccentrically stiffened plates are widely used as components of structural systems in civil, aerospace, marine and automotive industries. Stiffeners are commonly attached to plates along the major load-carrying direction to achive higher stiffness/weigth and stength/weigth ratios. To increase further, laminated composites have been first introduced in the aerospace industry, and currently being used in the civil engineering infrastructure such as bridge decks, bridges girders, strenghening and retrofitting existing structures, etc.

A number of analytical and numerical models for the analysis of stiffened plates have been proposed in the literature such as Kirk [1], Satsangi [6], Mukhopadhyay [2], Ghosh and Biswal [4], Chao and Lee [5], Kolli [12], Satish Kumar [9], Gangadhara Prusty [8] etc.

Among all the numerical methods, the finite element method (FEM) has been found to be reasonably accurate with less complexity to model stiffened plates. A more accurate model is achieved by representing the plate and stiffeners separately and maintaining compatibility between them. Thomson [3] et al. and Satsangi [6] used 8-noded rectangular plate elements and assumed that the stiffeners follow the same displacement field as that of the plating. The FE model of Kolli [12] consists of the 9-noded rectangular plate element and 3-noded beam element, the beams are placed along the plate nodal lines. Edward et al. [7] used a stiffened plate element that is composed of a rectangular 9-noded rectangular plate element and a number of 3-noded stiffener elements placed within the plate element and parallel to the element edges. Gangadhara Prusty [8] studied linear static analysis of composite hat-stiffened laminated shells using 8-noded rectangular plate element and 3noded beam element. The existing finite element techniques stimulate the stiffener to pass along the plate nodal lines. In these studies, no discussion has been made for the stiffeners of various shapes and having arbitrary orientation in the plate. To overcome this problem, 
Satish Kumar and Mukhopadhyay [9] have developed a stiffened triangular plate element for the analysis of laminated stiffened plates. This basic plate element is a combination of Allman's plane stress triangular element and discrete Kirchhoff-Mindlin plate bending element. However, the interpolation of displacements in their model is very complex and the natural frequencies obtained are less accurate than those published. In an attempt to efficiently solve this problem, we developed a new 6-noded stiffened laminated triangular element. This element can accommodate any number of arbitrarily oriented stiffeners of rectangular and closed (hat) sections, and is completely free from the usual constraints on the mesh division of the stiffened plates.

\section{FINITE ELEMENT FORMULATION}

\subsection{Stiffness matrix of the stiffened plate element}

The displacement field based on the first-order shear deiormation plate theory is given by

$$
\begin{aligned}
& u(x, y, z, t)=u^{0}(x, y, t)+z \theta_{x}(x, y, t) \\
& v(x, y, z, t)=v^{0}(x, y, t)+z \theta_{y}(x, y, t) \\
& w(x, y, z, t)=w^{0}(x, y, t)
\end{aligned}
$$

The displacement field of stiffener:

$$
\begin{aligned}
& u(\bar{x}, z, t)=u^{0}(\bar{x}, t)+z \theta_{\bar{x}}(\bar{x}, t) \\
& w(\bar{x}, t)=w^{0}(\bar{x}, t)
\end{aligned}
$$

here, $\bar{x}$ is $x$ - axis of stiffener. In general, $\angle(x, \bar{x})=\varphi$ as shown in Fig. 1 .

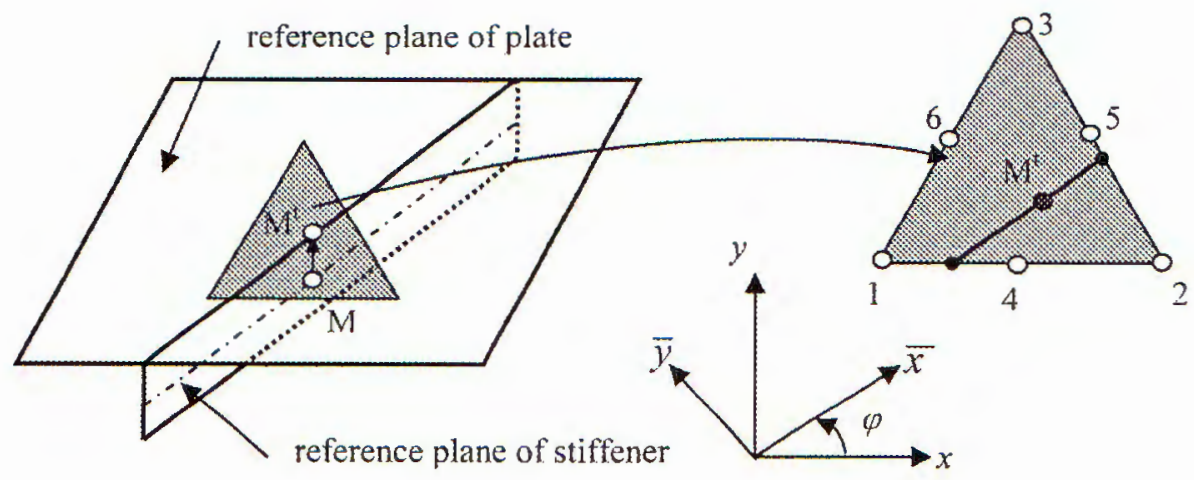

Fig. 1. Triangular stiffened plate element

The element stiffness matrix of stiffened plate is determined by:

$$
K_{e}=K_{e}^{p}+K_{e}^{s t},
$$

where $K_{e}^{p}$ and $K_{e}^{s t}$ are the element stiffness of flat plate and stiffener respectively and given by [10]:

$$
\begin{gathered}
K_{e}^{p}=\int_{S t}\left[B_{1}^{T} A_{1}^{B}+B_{1}^{T} B B_{2}+B_{2}^{T} B B_{1}+B_{2}^{T} D B_{2}+B_{3}^{T} A^{\prime} B_{3}\right] d S \\
K_{e}^{s t}=b_{s t} \int_{\ell s t}\left[B^{s t}\right]^{T}\left[T^{s t}\right]^{T}\left[D^{s t}\right]\left[T^{s t}\right]\left[B^{s t}\right] d \bar{x}
\end{gathered}
$$


$A, B, D$ and $A^{\prime}$ are the popular matrices of laminated composite [11]; $D^{s t}$ is the rigidity matrix of the stiffener; $b_{s t}$ is the width of stiffener; $B_{i}$ is the strain-displacement matrix of the plate:

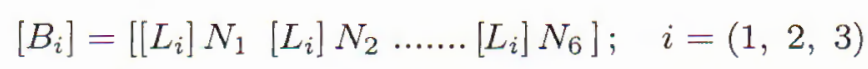

$N_{i}$ are quadratic shape functions; $B^{s t}$ is the strain-displacement matrix of the stiffener and is given by:

$$
\left[B^{s t}\right]=\left[\begin{array}{ccccccccc}
\frac{\partial}{\partial \bar{x}} & 0 & \frac{\partial}{\partial \bar{y}} & 0 & 0 & 0 & 0 & 0 & 0 \\
0 & \frac{\partial}{\partial \bar{y}} & \frac{\partial}{\partial \bar{x}} & 0 & 0 & 0 & 0 & 0 & 0 \\
0 & 0 & 0 & 0 & 0 & 0 & 0 & \frac{\partial}{\partial \bar{y}} & \frac{\partial}{\partial \bar{x}} \\
0 & 0 & 0 & \frac{\partial}{\partial \bar{x}} & 0 & 0 & \frac{\partial}{\partial \bar{y}} & 0 & 1 \\
0 & 0 & 0 & 0 & \frac{\partial}{\partial \bar{y}} & \frac{\partial}{\partial \bar{x}} & 0 & 1 & 0
\end{array}\right][\bar{N}]
$$

$T^{s t}$ is the transformation matrix of stiffener strain [10]:

$$
\left\{T^{s t}\right\}=\left[\begin{array}{ccccccccc}
\cos ^{2} \varphi & \sin ^{2} \varphi & \frac{1}{2} \sin 2 \varphi & 0 & 0 & 0 & 0 & 0 & 0 \\
0 & 0 & 0 & \cos ^{2} \varphi & \sin ^{2} \varphi & \frac{1}{2} \sin 2 \varphi & \frac{1}{2} \sin 2 \varphi & 0 & 0 \\
0 & 0 & 0 & 0 & 0 & 0 & 0 & \sin \varphi & \cos \varphi
\end{array}\right]
$$

The rigidity matrix of the stiffener due to parallel laminations: The rigidity matrix of the stiffener is expressed as

$$
\left[D^{s t}\right]=\left[\begin{array}{ccc}
A^{s t} & B^{s t} & 0 \\
B^{s t} & D^{s t} & 0 \\
0 & 0 & A^{\prime s t}
\end{array}\right],
$$

where, the coefficients of rigidity matrix are calculated by ignoring the stresses in the width or $\bar{y}$ direction of stiffener $\left(\sigma_{\bar{y}}=\tau_{\bar{x} \bar{y}}=\tau_{\bar{x} z}=0\right)$ but not the strains $\left(\varepsilon_{\bar{y}} \neq \gamma_{\bar{x} \bar{y}} \neq \gamma_{\bar{y} z} \neq 0\right)$ :

$$
\begin{aligned}
& A^{s t}=\sum_{\bar{k}=1}^{n_{s t}}\left[C_{11}^{\prime s t}-C_{12}^{\prime s t}\left(\bar{C}_{22}^{s t} C_{12}^{\prime s t}+\bar{C}_{26}^{\prime s t} C_{16}^{\prime s t}\right)-C_{12}^{\prime s t}\left(\bar{C}_{26}^{\prime s t} C_{12}^{\prime s t}+\bar{C}_{66}^{\prime s t} C_{16}^{\prime s t}\right)\right]_{k}\left(z_{k+1}-z_{k}\right) \\
& B^{s t}=\sum_{\bar{k}=1}^{n_{s t}}\left[C^{\prime s t}-C_{11}^{\prime s t}\left(\bar{C}_{12}^{\prime s t} C_{22}^{\prime s t}+\bar{C}_{12}^{\prime s t}{ }_{26}^{\prime s t}{ }_{16}^{s t}\right)-C_{12}^{\prime s t}\left(\bar{C}_{26}^{s t} C^{\prime s t}+\bar{C}_{12}^{\prime s t} C_{66}^{\prime s t}{ }_{16}\right)\right]_{k} \frac{z_{k+1}^{2}-z_{k}^{2}}{2} \\
& D^{s t}=\sum_{\bar{k}=1}^{n_{s t}}\left[C^{\prime s t}-C_{11}^{\prime s t}\left(\bar{C}_{12}^{\prime s t}{ }_{22}^{\prime s t}{ }_{12}+\bar{C}^{\prime s t}{ }_{26}^{\prime s t}{ }_{16}^{s t}\right)-C^{\prime s t}\left(\bar{C}_{12}^{\prime s t}{ }_{26}^{\prime s t}{ }_{12}+{\overline{C^{\prime}}}_{66}^{s t}{C^{\prime}}_{16}^{s t}\right)\right]_{k} \frac{z_{k+1}^{3}-z_{k}^{3}}{3} \\
& A^{\prime s t}=\sum_{\bar{k}=1}^{n_{s t}}\left[C_{55}^{\prime s t}-\frac{\left(C_{45}^{\prime s t}\right)^{2}}{C_{44}^{\prime s t}}\right]_{k}\left(z_{k+1}-z_{k}\right)
\end{aligned}
$$

$C_{i j}^{\prime s t} \quad(i, j=1,2,3,4,5$ and 6$)$ are the stiffness coefficients of the stiffener material and

$$
\left[\begin{array}{cc}
\bar{C}_{22}^{\prime s t} & \bar{C}_{26}^{\prime s t} \\
\bar{C}_{26}^{\prime s t} & \bar{C}_{66}^{\prime s t}
\end{array}\right]=\left[\begin{array}{ll}
C_{22}^{\prime s t} & C^{\prime s t} \\
C_{26}^{\prime s t} & C_{66}^{\prime s t}
\end{array}\right]^{-1}
$$


The rigidity matrix of the stiffener due to perpendicular laminations: The rigidity matrix of the stiffener is expressed as

$$
\left[D^{s t}\right]=\sum_{k=1}^{n}\left[\begin{array}{ccc}
\left(C_{11}^{\prime s t}\right)_{k} d_{s} & 0 & 0 \\
0 & \left(C_{11}^{\prime s t}\right)_{k} \frac{d_{s}^{3}}{12} & 0 \\
-2\left(C_{16}^{\prime s t}\right)_{k} d_{s} & 0 & \left(C_{66}^{\prime s t}\right)_{k} d_{s}
\end{array}\right]
$$

where $d_{s}$ is the height or depth of the stiffener.

\subsection{Mass matrices}

a. Mass matrix of the plate element

The kinetic energy of plate element with distributed mass is given by:

$$
T_{e}=\frac{1}{2} \int_{V e} \dot{\mathbf{u}}^{T} \rho \dot{\mathbf{u}} d V
$$

where

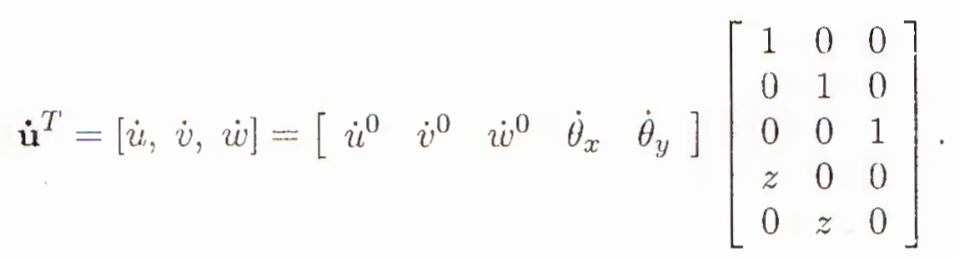

We can express $\mathbf{u}$ in terms of the nodal displacements, $a$, by using shape functions $N$ :

$$
T_{e}=\frac{1}{2} \int_{S e}\{\dot{d}\}^{T}\left[\rho^{*}\right]\{\dot{d}\} d S=\frac{1}{2} \int_{S e}\{\dot{a}\}^{T}[N]^{T}\left[\rho^{*}\right][N]\{\dot{a}\} d S=\frac{1}{2}\{\dot{a}\}^{T}\left[M_{e}\right]\{\dot{a}\}
$$

where $\left[M_{e}\right]$ is the mass matrix of plate element:

$$
\left[M_{e}\right]=\int_{S e}[N]^{T}\left[\rho^{*}\right][N] d S
$$

and

$$
[\rho *]=\left[\begin{array}{ccccc}
I_{0} & & & & \\
0 & I_{0} & & \text { Sym } & \\
0 & 0 & I_{0} & & \\
I_{1} & 0 & 0 & I_{2} & \\
0 & I_{1} & 0 & 0 & I_{2}
\end{array}\right]
$$

with

$$
\left(I_{0}, I_{1}, I_{2}\right)=\sum_{k=1}^{n} \rho_{k} \int_{h_{k}}^{h_{k+1}}\left(1, z, z^{2}\right) d z
$$


$N=\left[\begin{array}{cccccccccccccccc}N_{1} & 0 & 0 & 0 & 0 & N_{2} & 0 & 0 & 0 & 0 & \cdots & N_{6} & 0 & 0 & 0 & 0 \\ 0 & N_{1} & 0 & 0 & 0 & 0 & N_{2} & 0 & 0 & 0 & \cdots & 0 & N_{6} & 0 & 0 & 0 \\ 0 & 0 & N_{1} & 0 & 0 & 0 & 0 & N_{2} & 0 & 0 & \cdots & 0 & 0 & N_{6} & 0 & 0 \\ 0 & 0 & 0 & N_{1} & 0 & 0 & 0 & 0 & N_{2} & 0 & \cdots & 0 & 0 & 0 & N_{6} & 0 \\ 0 & 0 & 0 & 0 & N_{1} & 0 & 0 & 0 & 0 & N_{2} & \cdots & 0 & 0 & 0 & 0 & N_{6}\end{array}\right]$

b. Mass matrix of the stiffener member

The kinetic energy of stiffener member with distributed mass is given by:

$$
T_{s t}=\frac{1}{2} \int_{V e} \dot{\mathbf{u}}_{s t}^{T} \rho \dot{\overline{\mathbf{u}}}_{s t} d V
$$

The $\dot{\mathbf{u}}_{s t}$ can be expressed by

$$
\dot{\overline{\mathbf{u}}}_{s t}^{T}=\left[\dot{\bar{u}}_{s t}, \dot{\bar{w}}_{s t}\right]=\left[\begin{array}{ccc}
\dot{\bar{u}}_{s t}^{0} & \dot{\bar{w}}_{s t}^{0} & \dot{\bar{\theta}}_{\bar{x}_{s t}}
\end{array}\right]\left[\begin{array}{cc}
1 & 0 \\
0 & 1 \\
z & 0
\end{array}\right] .
$$

These terms in plate element coordinates are expressed as

$$
\left[\begin{array}{c}
\bar{u}_{s t} \\
\bar{w}_{s t}
\end{array}\right]=\left[\begin{array}{ccccc}
\cos \varphi & \sin \varphi & 0 & z \cos \varphi & z \sin \varphi \\
0 & 0 & 1 & 0 & 0
\end{array}\right]\left[\begin{array}{c}
u_{s t}^{0} \\
v_{s t}^{0} \\
w_{s t}^{0} \\
\theta_{x_{s t}} \\
\theta_{y_{s t}}
\end{array}\right]
$$

The displacement compatibility between the stiffener and the plate is ensured by the beam displacement field which is interpolated from plate element's nodal displacements by:

$$
\left[\begin{array}{c}
u_{s t}^{0} \\
v_{s t}^{0} \\
w_{s t}^{0} \\
\theta_{x_{s t}} \\
\theta_{y_{s t}}
\end{array}\right]=\left[\begin{array}{lllll}
1 & 0 & 0 & \delta & 0 \\
0 & 1 & 0 & 0 & \delta \\
0 & 0 & 1 & 0 & 0 \\
0 & 0 & 0 & 1 & 0 \\
0 & 0 & 0 & 0 & 1
\end{array}\right]\left[\begin{array}{c}
u^{0} \\
v^{0} \\
w^{0} \\
\theta_{x} \\
\theta_{y}
\end{array}\right]
$$

where $\delta=\frac{H+h}{2}$ is eccentricity; $h$ is thickness of plate and $H$ is height of stiffener.

Finally

$$
T^{s t}=\frac{1}{2} b_{s t} \int_{l_{s t}}\{\dot{d}\}^{T}[\bar{\rho}]\{\dot{d}\} d \bar{x}=\frac{1}{2} b_{s t} \int_{l_{s t}}\{\dot{a}\}^{T}[\bar{N}]^{T}[\bar{\rho}][\bar{N}]\{\dot{a}\} d \bar{x}=\frac{1}{2}\{\dot{a}\}^{T}\left[M_{s t}\right]\{\dot{a}\}
$$

and $\quad\left[M_{s t}\right]$ is mass matrix of stiffener component:

$$
\left[M_{s t}\right]=b_{s t} l_{s t}[\bar{N}]^{T}[\bar{\rho}][\bar{N}]
$$


where

$$
[\bar{\rho}]=\sum_{k=1}^{n_{s t}} \rho_{k_{s t}} \int_{h_{k s t}}^{h_{k+1} s t}\left[\begin{array}{ccccc}
\cos ^{2} \varphi & \cos \varphi \sin \varphi & 0 & z \cos ^{2} \varphi & z \cos \varphi \sin \varphi \\
& \sin ^{2} \varphi & 0 & z \cos \varphi \sin \varphi & z \sin ^{2} \varphi \\
& & 1 & 0 & 0 \\
& S y m & & z^{2} \cos ^{2} \varphi & z^{2} \cos \varphi \sin \varphi \\
& & & & z^{2} \sin ^{2} \varphi
\end{array}\right] d z
$$

and

$$
[\bar{N}]=\left[\begin{array}{lllll}
1 & 0 & 0 & \delta & 0 \\
0 & 1 & 0 & 0 & \delta \\
0 & 0 & 1 & 0 & 0 \\
0 & 0 & 0 & 1 & 0 \\
0 & 0 & 0 & 0 & 1
\end{array}\right][N]
$$

\section{RESULTS AND DISCUSSIONS}

\subsection{Validation of the model}

\section{Example 1}

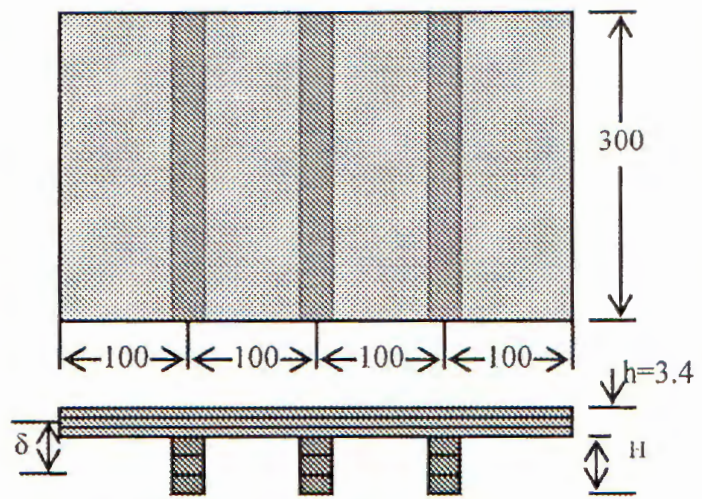

Fig. 2. Laminated stiffened plates, eccentricity is variable

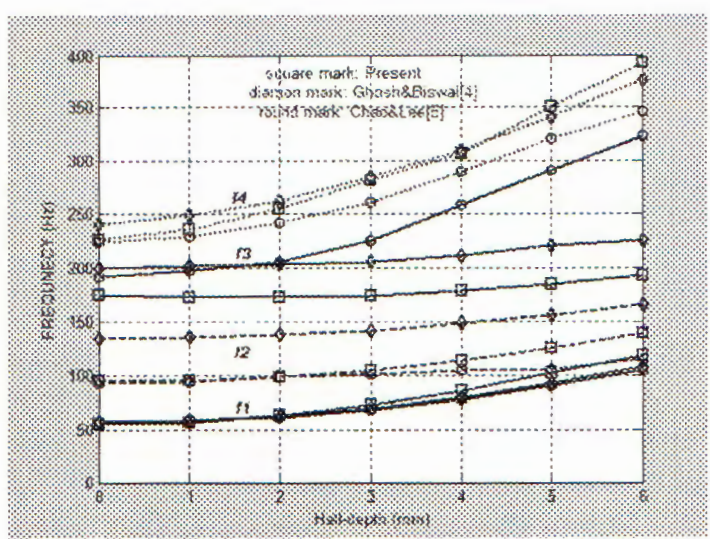

Fig. 3. Frequency vs, half-depth of stiffeners

In order to check the reliability and accuracy of the present element, we consider the free vibration of a simply supported blade stiffened plates. The variation of natural frequencies with stiffener eccentricity are presented for specially orthotropic cross-ply laminates with three equally spaced stiffeners (Fig. 2). The geometry of the stiffened laminates is $a \times b \times h=400 \times 300 \times 3.4\left(\mathrm{~mm}^{3}\right)$; the lamination of plate and stiffeners is $\left(90^{0} / 0^{0} / 90^{0}\right)_{T}$

The ply properties: $\mathrm{E}_{1}=9.71 \mathrm{GPa} ; \mathrm{E}_{2}=3.25 \mathrm{GPa} ; \mathrm{G}_{12}=\mathrm{G}_{13}=0.9025 \mathrm{GPa} ; \mathrm{G}_{23}$ $=0.2356 \mathrm{GPa} ; \nu_{12}=0.29 ; \rho=1347 \mathrm{~kg} / \mathrm{m}^{3}$ for both the plate and the stiffener. The width of stiffener is $3 \mathrm{~mm}$. The numerical results are compared with those of Ghosh and Biswal [4] (4-noded rectangular element with 7 d.o.f at each node) and Chao and Lee [5]. The variation of natural frequencies with stiffener half-depth (Fig. 3) shows better agreement with those of Ghosh and Biswal than those of Chao and Lee [5]. This may be due to neglecting of the shear effects by Chao and Lee. 
Example 2. Free vibration of a cross-stiffened plate

The geometry of cross-stiffened plate is $a=b=254 \mathrm{~mm}, h=12.7 \mathrm{~mm}, \dot{d}_{s x}=d_{s y}=25.4$ $\mathrm{mm}, b_{s x}=b_{s y}=6.35 \mathrm{~mm}$. Where, $d_{s x}, b_{s x}$ is depth and width of the $x$-direction stiffener; $d_{s y}, b_{s y}$ is depth and width of the $y$-direction stiffener. The following ply properties of AS4/3501 graphite/epoxy composites are used: $E_{1}=144.8 \mathrm{GPa} ; E_{2}=9.67 \mathrm{GPa} ; G_{12}=$ $G_{13}=4.14 \mathrm{GPa} ; G_{23}=3.45 \mathrm{GPa} ; \nu_{12}=0.3 ; \rho=1389.23 \mathrm{~kg} / \mathrm{m}^{3}$.

The stiffener laminations are parallel to the plate midplane. The frequencies of the first four modes of various boundary conditions of a $(0 / 90)$ cross-stiffened plate are presented in Table 1 and they are compared with those reported in [9], [13] and [14], using $10 \times 10$ mesh for full plate. The fundamental frequencies showed good agreement with those of [9], whereas the frequencies of higher modes compared excellently with those of [14]. According to analysis of [9], the author of [13] used the reduced stiffness coefficients in the rigidity matrix of the stiffener which reduced its stiffness. Moreover, they have ignored the coupling coefficients in the strain-energy of the stiffener element. Therefore, the fundamental frequencies of lower modes with the present element are higher than that of [13].

Table 1. Effect of boundary conditions on natural frequencies $(\mathrm{Hz})$ of $(0 / 90)$ cross-stiffened plates.

\begin{tabular}{|c|c|c|c|c|c|}
\hline $\begin{array}{c}\text { Boundary } \\
\text { conditions }\end{array}$ & $\begin{array}{c}\text { Mode } \\
\text { no }\end{array}$ & Present & Ref. [9] & Ref. [13] & Ref. [14] \\
\hline \multirow{3}{*}{ SSSS } & 1 & 1063.6 & 1076.0 & 961.81 & 1092.64 \\
\cline { 2 - 6 } & 2 & 2132.5 & 2059.6 & 1954.41 & 1837.04 \\
\cline { 2 - 6 } & 3 & 2263.0 & 2302.7 & 2325.41 & 2491.85 \\
\cline { 2 - 6 } & 4 & 2619.8 & 2635.8 & 2641.18 & 2654.51 \\
\hline \multirow{4}{*}{ CCCC } & 1 & 1693.9 & 1666.5 & 1583.50 & 1753.79 \\
\cline { 2 - 6 } & 2 & 3026.1 & 2929.2 & 2831.53 & 2716.65 \\
\cline { 2 - 6 } & 3 & 3102.8 & 3140.1 & 3165.27 & 3319.93 \\
\cline { 2 - 6 } & 4 & 3635.3 & 3666.3 & 3634.62 & 3686.53 \\
\hline
\end{tabular}

\subsection{Experimental study}

Let's consider a stiffened rectangular composite plate made of glass fiber/polyester 3210 with lamination [M300/WR800/M300/WR800/M450]. Where, M300 denotes glass fiber in Mat form, which its weight per unit area is $300 \mathrm{~g} / \mathrm{m}^{2} ;$ M450 denotes glass fiber in Mat form, which its weight per unit area is $450 \mathrm{~g} / \mathrm{m}^{2}$ and WR800 denotes glass fiber in WR form, which its weight per unit area is $800 \mathrm{~g} / \mathrm{m}^{2}$. The sides of plate are $a \times b=$ $800 \times 500 \mathrm{~mm}^{2}$. The plate is reinforced by 6 longitudinal $\left(n_{x}=6\right)$ and 9 transverse $\left(n_{y}\right.$ $=9$ ) hat stiffeners (Fig. 4). The stiffeners were made by glass fiber in Mat and have the same sizes as follows: $b_{s t} \times h_{s t} \times t_{s t}=10 \times 20 \times 1.8\left(\mathrm{~mm}^{3}\right)$.

Three first natural frequencies of unstiffened and stiffened plates subjected to various boundary conditions were measured by "Multi- vibration measuring machine" DEWE BOOK-DASYLab 5.61.10 and are given in Table 2. 


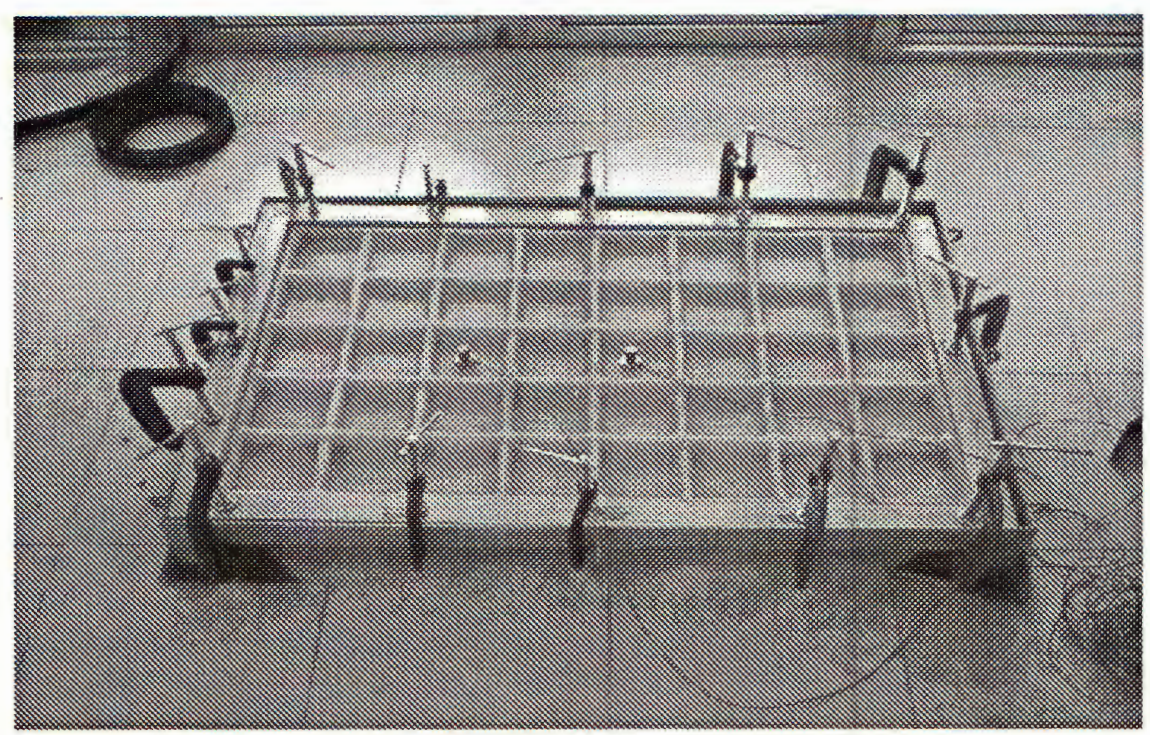

Fig. 4. Experimental set-up and testing procedure for stiffened composite plate

Table 2. Experimental results on natural frequencies $(\mathrm{Hz})$ of stiffened composite plate [15]

\begin{tabular}{|c|c|c|c|c|c|}
\hline Plates & $\begin{array}{c}\text { Mode } \\
\text { no }\end{array}$ & $\begin{array}{c}\text { Clamped } \\
\text { at 4 edges }\end{array}$ & $\begin{array}{c}\text { CC at x-edges } \\
\text { SS at y-edges }\end{array}$ & $\begin{array}{c}\text { CC at y-edges } \\
\text { SS at x-edges }\end{array}$ & $\begin{array}{c}\text { Simply } \\
\text { Supported } \\
\text { at 4 edges }\end{array}$ \\
\hline \multirow{3}{*}{ Unstiffened } & 1 & 36.430 & 34.595 & 22.620 & 18.310 \\
\cline { 2 - 6 } & 2 & 53.560 & 45.770 & 43.600 & 33.530 \\
\cline { 2 - 6 } & 3 & 82.320 & 68.510 & 61.030 & 59.380 \\
\hline \multirow{3}{*}{ Stiffened } & 1 & 147.660 & 139.280 & 82.070 & 65.460 \\
\cline { 2 - 6 } & 2 & 206.330 & 168.630 & 166.500 & 118.640 \\
\cline { 2 - 6 } & 3 & 322.370 & 259.810 & 242.080 & 225.135 \\
\hline
\end{tabular}

\subsection{Finite element results and comparison}

In this section, we calculate the natural frequencies for above stiffened composite plate by our computer program. The first three natural frequencies will be compared with those of experimental ones.

The elastic constants of material used in the calculation were determined by our mechanical tests [16].

For a Mat layer: $E_{11}=E_{22}=4.807 \mathrm{GPa} ; G_{12}=2.05 \mathrm{GPa} ; \nu_{12}=0.17$.

For a WR layer $\left(0^{\circ}\right.$ and $\left.90^{\circ}\right): E_{11}=10.58 \mathrm{GPa} ; E_{22}=2.64 \mathrm{GPa} ; G_{12}=1.02 \mathrm{GPa}$; $\nu_{12}=0.17$.

Thickness of a M300 layer, $t_{M 3}=0.6 \mathrm{~mm}$; thickness of a M450 and WR8 layer, $t_{M 45}$ $=t_{W R 8}=1 \mathrm{~mm}$.

The laminations of stiffeners are parallel to the plate midplane. The frequencies of the first three modes of various boundary conditions of a cross-stiffened plate using $12 \times 12$ mesh for full plate are presented in Table 3 and they are compared with those reported in 
[15] in Fig. 5 and Fig. 6. The fundamental frequency of clamped plate at 4 edges shown very good agreement with those of [15], whereas the frequencies of simply supported plate at 4 edges are higher than that of [15]. This may be due to the boundary condition constructed in experimental study (not simply supported absolutely).

Table 3. Natural frequencies-NF (Hz) of stiffened plates calculated by finite element program.

\begin{tabular}{|c|c|c|c|c|c|}
\hline Plates & $\begin{array}{c}\text { Mode } \\
\text { no }\end{array}$ & $\begin{array}{c}\text { Clamped } \\
\text { at 4 edges }\end{array}$ & $\begin{array}{c}\text { CC at x-edges } \\
\text { SS at y-edges }\end{array}$ & $\begin{array}{c}\text { CC at y-edges } \\
\text { SS at x-edges }\end{array}$ & $\begin{array}{c}\text { Simply } \\
\text { Supported } \\
\text { at } 4 \text { edges }\end{array}$ \\
\hline \multirow{3}{*}{ Unstiffened } & 1 & 38.749 & 35.485 & 24.420 & 19.639 \\
\cline { 2 - 6 } & 2 & 58.708 & 47.660 & 45.560 & 37.201 \\
\cline { 2 - 6 } & 3 & 93.653 & 70.490 & 63.020 & 63.855 \\
\hline \multirow{3}{*}{ Stiffened } & 1 & 158.173 & 141.240 & 84.110 & 78.357 \\
\cline { 2 - 6 } & 2 & 219.784 & 170.720 & 167.390 & 139.836 \\
\cline { 2 - 6 } & 3 & 328.392 & 261.590 & 251.140 & 245.759 \\
\hline
\end{tabular}

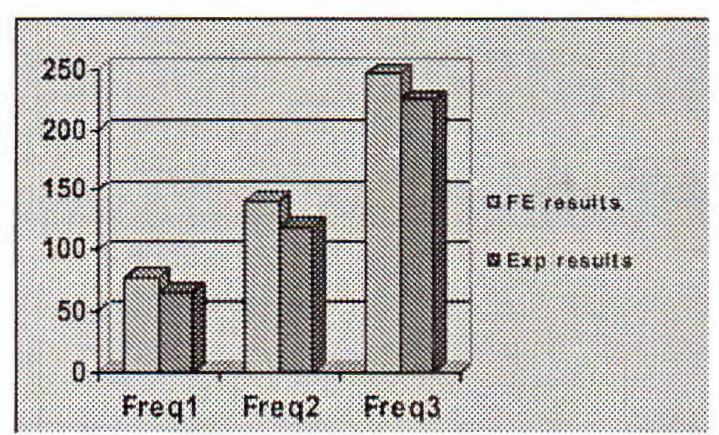

Fig. 5. Comparision of NF of simply supported plate

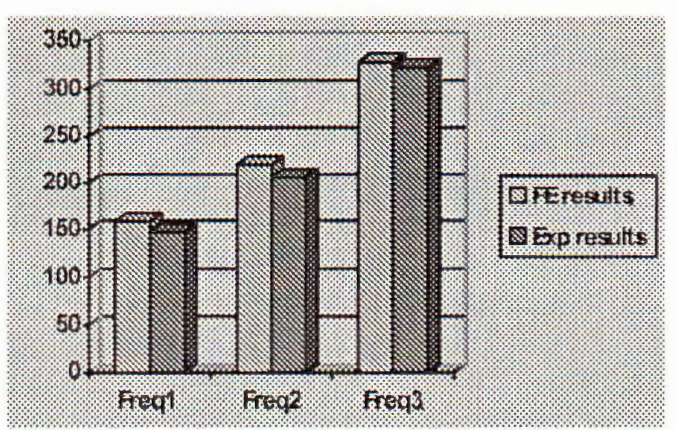

Fig. 6. Comparision of NF of clamped plate

\section{CONCLUSIONS}

In this paper, we have presented a new 6-noded stiffened triangular plate element for vibration analysis of laminated composite plate with laminated stiffeners. The stiffener is elegantly modeled and does not introduce any additional nodes. The plate element entertains any number of arbitrary oriented stiffener elements and eliminates the usual constraints imposed on the mesh division of stiffened plates. The model is validated by comparing with existing results documented in the literature. Some problems on free vibration analyses of laminated stiffened plates made of graphite/epoxy and glass/polyester are analyzed with the present element. Moreover, the element has been very effective in analysis of both thin and moderately thick plates. The finite element results compare well with experimental ones. It is recommended that the present formulation can be used to determine the fundamental frequencies required in the design and analysis of eccentric composite stiffened plates.

This publication is the results of National Basic Research Project supported by Ministry of Science and Technology. 


\section{REFERENCES}

1. C. L. Kirk, Vibration of centrally placed stiffened rectangular plates, J. R Aero Soc. 65 (1961) 695-7.

2. M. Mukhopadhyay, Vibration and stability of analysis of stiffened plates by semi-analytic finite difference method, J. Sound Vibr. 130 (1989) 41-53.

3. P. A. Thomson, P. Bettess, J. B. Caldwell, An isoparametric eccentrically stiffened plate bending element. Engng Comput 5 (1988) 110-6.

4. A. K. Ghosh, K. C. Biswal, Finite element analysis for stiffened laminated plates using higher order shear deformation theory, Computers and Structures 53 (1994) 161-171.

5. C. C. Chao, J. C. Lee, Vibration of eccentrically stiffened laminates, Journal of Composite Materials 14(2.3) (1980) 233-244.

6. S. K. Satsangi, M. Mukhopadhyay, Finite element state analysis of girder bridges having arbitrary platform, Int Ass for Bridge Struct Engng 17 (1987) 65-94.

7. Edward A. Sadeck, Samer A. Tawfik, A finite element model for the analysis of stiffened laminated plates, Computers and Structures (2000) 369-383.

8. B. Gangadhara Prusty, Linear static analysis of hat-stiffened laminated shells using finite elements, Finite elements in analysis and design 39 (2003) 1125-1138.

9. Y. V. Satish Kumar, M. Mukhopadhyay, A new triangular stiffened plate element for laminate analysis, Composite Science and Technology 60 (2000) 935-943.

10. Ngo Nhu Khoa, Calculation of laminated composite stiffened-plate using finite element method, Jounal of science and technology 3 (1) (2007) (in Vietnamese).

11. Tran Ich Thinh, Composite Materials: Mechanics of Materials and Structures. Ed. Education, 1994, (In Vietnamese).

12. M. Kolli, K. Chandrashekhara, Finite element analysis of stiffened laminated plates under transverse loading, Composites Science and Technology 56 (1996) 1355-1361, USA.

13. K. Chandrasekhara, M. Kolli, Free vibration of eccentrically stiffened laminated plates, Journal of Reinforced Plastics and Composites 16 (11) (1997) 884-902.

14. C. Ray, Analysis of hat-stiffened composite plates by Finite element method, PhD thesis, Indian Institute of Technology, Kharagpur, 1998.

15. Nguyen Van Dat, Studing the reasonable constructure of stand system of fishing ship hull to support to vibration, $P h D$ thesis, 2005 (in Vietnamese).

16. Tran Ich Thinh, Tran Minh Tu, Experimental determination of mechanical properties of glass/polyester composite, Vietnam Jounal of Science and Technology 43 (7) (2005).

Received October 22, 2007

\section{MỘT LOẠI PHẦN TƯ TẤM GÂN MỚI TRONG PHÂN TÍCH DAO DộNG TỰ DO CƯA TẤM COMPOSITE CÓ GÂN GIA CƯỜNG}

Báo cáo giới thiệu một loại phần tự tấm gân gia cường mới để phân tích dao động tự do của tấm composite có gân gia cường dựa vào lý thuyết biến dạng của Mindlin. Phần tự tấm gân được xem là tổ hợp của phần tự tấm tam giác 6 nút và dầm (không phải phần tử dầm). Phần tử tấm gân chấp nhận số gân bất kỳ và hướng của gân tuỳ ý trong nó. Điều này cho phép ta chọn lưới phần tự tuỳ ý cho tấm gân để tính toán. Kết quả tính toán tần số dao động tự do của tấm gân composite lớp bằng các phần tử nói trên rất tương đồng với một số kết quả đã công bố của các tác giả khác. Kết quá tính toán dao động của tấm gân thuý tinh/polyester chịu các liên kết khác nhau bằng phần tự hữu hạn phù hợp với kết quả thực nghiệm. 